\title{
Exertion of stairclimbing in normal subjects and in patients with chronic obstructive bronchitis
}

\author{
A. N. JOHNSON, ${ }^{1}$ D. F. COOPER, ${ }^{2}$ AND R. H. T. EDWARDS ${ }^{3}$ \\ From the Department of Medicine, Royal Postgraduate Medical School, \\ Du Cane Road, London W12 OHS, UK
}

\begin{abstract}
Johnson, A. N., Cooper, D. F., and Edwards, R. H. T. (1977). Thorax, 32, 711-716. Exertion of stairclimbing in normal subjects and in patients with chronic obstructive bronchitis. The exertion of stairclimbing has been studied in 10 normal young men, 10 healthy middle-aged men, and 10 middle-aged men with chronic bronchitis. Subjects climbed a staircase with a total vertical ascent of $40.8 \mathrm{~m}$. They were allowed to adopt the most comfortable pattern of ascent, the patients having to stop at intervals for rest pauses. Work rate was determined by timing the raising of body weight over measured sections of the staircase. Perception of exertion estimated with a numerical scale, heart rate, and increase of blood lactate concentration were closely similar in all three groups at the top of the staircase. In the patients, average power output was directly dependent on lung function, as indicated by the forced expired volume in 1 second. Stairclimbing offers a simple way of studying a patient's spontaneous activity pattern in a 'real life' environment. Studies of the kind described here could usefully complement formal exercise testing in the laboratory.
\end{abstract}

Stairclimbing is one of the most taxing of habitual activities yet it has been relatively little studied. Waller and de Decker (1919), Hill and Lupton (1923), and Benedict and Parmenter (1928) have measured the energy cost of walking up stairs, Margaria et al. (1966) and Davies (1971) have used stair running to calculate power output in high work rates of short duration, and steps have been used widely in exercise tests. Work has been at either imposed rates or maximum rates and the study of preferred activity patterns in stairclimbing appears to have been neglected.

The introduction by Borg (1962) of his 'rating of perceived exertion scale' represents an attempt to use self-evaluation in the assessment of the sense of effort of physical work. A high correlation has been obtained between heart rate and rating of perceived exertion (Borg et al., 1968; Borg, 1971 ; Skinner et al., 1969; Edwards et al., 1972). This suggests that the ability to regulate work intensity in relation to perceived effort has been underestimated and that 'selfpacing' could be important in everyday activities. How an individual perceives the effort of everyday

\section{Present addresses:}

Department of Pharmacology, University College London, London WC1E 6BT, UK

'St. Mary's College, Strawberry Hill, Twickenham, Middx, UK

${ }^{3}$ Department of Human Metabolism, University College Hospital Medical School, University Street, London WC1E 6JJ, UK activities may yield valuable information which may usefully supplement the often used clinical question 'How many stairs can you climb?'

The purposes of this study were to determine the preferred rates of stairclimbing of normal subjects and patients with chronic airways obstruction, relating them to the 'maximum anaerobic power', and to examine the relationship between the perceived exertion and physiological indices of exertion. A preliminary account of a part of this study has already been published (Edwards, 1971).

\section{Methods}

\section{THE STAIRCASE}

The staircase was not ideal (spiral) but had a vertical height of 40.8 metres, spanned 12 floors, and comprised 240 equal steps arranged in 24 flights of 10 steps each with a small landing between each flight. As the staircase was narrow it was possible for subjects to walk continuously upstairs taking only one step on each landing.

The staircase was calibrated as follows: Each stair was numbered and the height and depth of three, randomly selected from each flight of 10 , were measured with a centimetre tape. In addition, the vertical height of every flight was measured with a 
plumb line. The angle of the slope of each flight was calculated by trigonometry. A calibration graph of vertical height (metres) against step number was constructed so that during the exercise test the subject's position on the staircase could be noted and the vertical distance through which his weight had been raised readily obtained. This was subsequently used to calculate power output during ascent.

\section{RATING OF PERCEIVED EXERTION}

The scale for rating perceived exertion was explained to the subjects before they started the ascent (Table 1).

\section{SUBJECTS}

The subjects studied comprised three groups: group 1, 10 healthy young men; group 2,10 healthy middleaged men; and group 3, 10 middle-aged men with chronic bronchitis.

Group 3 was selected by a clinician according to standard diagnostic criteria (Medical Research Council, 1965) from patients attending the Bronchitis Research Clinic at Hammersmith Hospital.

\section{INITIAL MEASUREMENTS}

Anthropometric, personal, and spirometric data are shown in Table 2.

Spirometric measurements in group 3 were taken three minutes after a standard administration of a bronchodilator since a slight degree of reversibility (average increase in forced expired volume in one second $\left(F E V_{1}\right) 0.15$ l) was present in most of the patients. This procedure was carried out before each

Table 1 Rating of perceived exertion scale (Borg, 1970)

\begin{tabular}{rlll}
\hline 6 & & 14 & \\
7 & Very, very light & 15 & Hard \\
8 & & 16 & \\
9 & Very light & 17 & Very hard \\
10 & & 18 & \\
11 & Fairly light & 19 & Very, very hard \\
12 & & 20 & \\
13 & Somewhat hard & & \\
\hline
\end{tabular}

Table 2 Anthropometry and spirometry of all patients studied (mean $\pm S E M$ )

\begin{tabular}{|c|c|c|c|}
\hline & $\begin{array}{l}\text { Group 1: } \\
\text { Young } \\
\text { normal } \\
\text { subjects } \\
(n=10)\end{array}$ & $\begin{array}{l}\text { Group 2: } \\
\text { Middle-aged } \\
\text { normal } \\
\text { subjects } \\
(n=10)\end{array}$ & $\begin{array}{l}\text { Group 3: } \\
\text { Middle-aged } \\
\text { patients } \\
(n=10)\end{array}$ \\
\hline $\begin{array}{l}\text { Age (yr) } \\
\text { Height (cm) } \\
\text { Weight (kg) } \\
\text { FEV } 1 \cdot 0 \text { (1 BTPS) } \\
\text { FVC (1 BTPS) } \\
\text { FEV } 1.0 \text { as percentage }\end{array}$ & $\begin{array}{r}23 \cdot 4 \pm 1 \cdot 6 \\
177 \cdot 0 \pm 1 \cdot 4 \\
71 \cdot 2 \pm 2 \cdot 3 \\
4 \cdot 51 \pm 0 \cdot 2 \\
5 \cdot 65 \pm 0 \cdot 2\end{array}$ & $\begin{array}{r}58 \cdot 3 \pm 0.9 \\
173.0 \pm 1.9 \\
74.8 \pm 2 \cdot 8 \\
3 \cdot 32 \pm 0 \cdot 2 \\
4 \cdot 35 \pm 0.3\end{array}$ & $\begin{array}{r}58 \cdot 3 \pm 2 \cdot 4 \\
166 \cdot 7 \pm 2 \cdot 2 \\
66 \cdot 3 \pm 3 \cdot 1 \\
0 \cdot 84 \pm 0 \cdot 1 \\
2 \cdot 59 \pm 0 \cdot 1\end{array}$ \\
\hline $\begin{array}{l}\text { predicted normal } \\
\text { FEV \% FVC } \\
\text { Mixed venous } \mathrm{PCO}_{2} \\
\text { (mmHg) }\end{array}$ & $\begin{array}{r}104 \cdot 6 \pm 3.9 \\
80 \cdot 0 \pm 2.9 \\
44.9 \pm 0.2\end{array}$ & $\begin{array}{r}103 \cdot 5 \pm 5 \cdot 2 \\
76 \cdot 0 \pm 2 \cdot 2 \\
45 \cdot 5 \pm 0 \cdot 3\end{array}$ & $\begin{array}{l}30.4 \pm 3.9 \\
32.0 \pm 2.8 \\
49.5 \pm 1.4\end{array}$ \\
\hline
\end{tabular}

exercise test. All patients were used to taking a음 bronchodilator preparation (salbutamol or isoprena- $\frac{\bar{c}}{\bar{N}}$ line) as part of the management of their chronic $\frac{\vec{\sigma}}{\vec{\sigma}}$ airways obstruction. Carbon dioxide tension in mixed $\mathrm{O}$ venous blood was estimated indirectly by the rebreathing method of Campbell and Howell (1962).

\section{CONDUCT OF PREFERRED RATES OF STAIRCLIMBING EXPERIMENT}

Before and after each trial the following data were $\times$ collected:

1 Resting and post-exercise heart rate (radial pulse palpation).

2 Blood lactate $(1 \mathrm{ml}$ blood from an antecubital

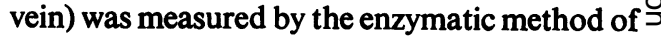
Hohorst (1962).

3 Peak expiratory flow (PEFR), Wright Peak Flowmeter. Rating of perceived exertion (RPE) (Borg, $\frac{\mathbb{D}}{3}$
1970).

Subjects were instructed to walk upstairs at a comfort- $\vec{\varphi}$ able pace, resting if necessary, and were at liberty to $\forall$ alter their rate of ascent. Overall time for the ascent was recorded and net power output was calculated by use of the following formula:

$$
\frac{\mathrm{W}=m \times h \times 60 \times 6 \cdot 12 \text { Watts }}{t}
$$

where $m=$ subject's weight in kilograms

$h=$ vertical height of stairs in metres

and $t=$ ascent time in seconds.

\section{MEASUREMENT OF MAXIMUM ANAEROBIC POWER}

The stair-running technique described by Margaria et al. (1966), and illustrated in Fig. 1, was used. Subjects were asked to run as fast as possible up the flight of 10 steps, two steps at a time. This ensured that both light beams would be interrupted by the same limb in approximately the same phase of movement. Two practice trials were allowed and the best of three successive attempts was recorded. A rest of two minutes was allowed between trials.

\section{Results}

\section{ANALYSIS OF PREFERRED RATES OF ASCENT}

The spontaneous ascent patterns adopted by each group as well as the patterns for the fastest and slowest member of each group are shown in Fig. 2. Patients were found to climb at a mean rate of $65.4 \pm 3.1$ steps per minute, which is equivalent to approximately $65 \%$ of the average stepping rate adopted by healthy young men, and $82 \%$ of that adopted by the middleaged men. The speed of climbing was remarkably constant in all groups. Patients tended to slow down $\varrho$ slightly after completing two-thirds of the ascent but 2 their stepping rate fell by only $6 \%$ of the value adopted 


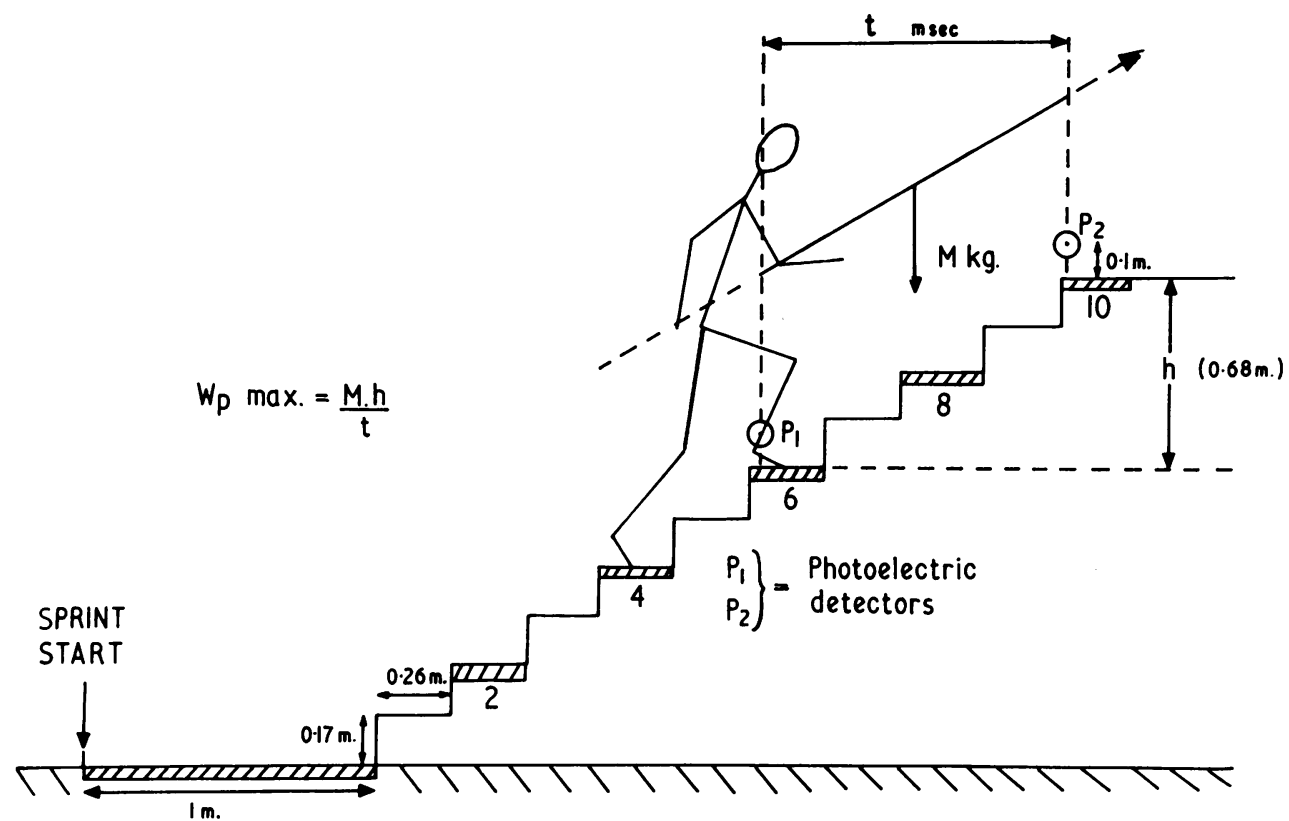

Fig. 1 Measurement of maximum anaerobic power (Wp max) by stair-running (after Margaria, et al., 1966).

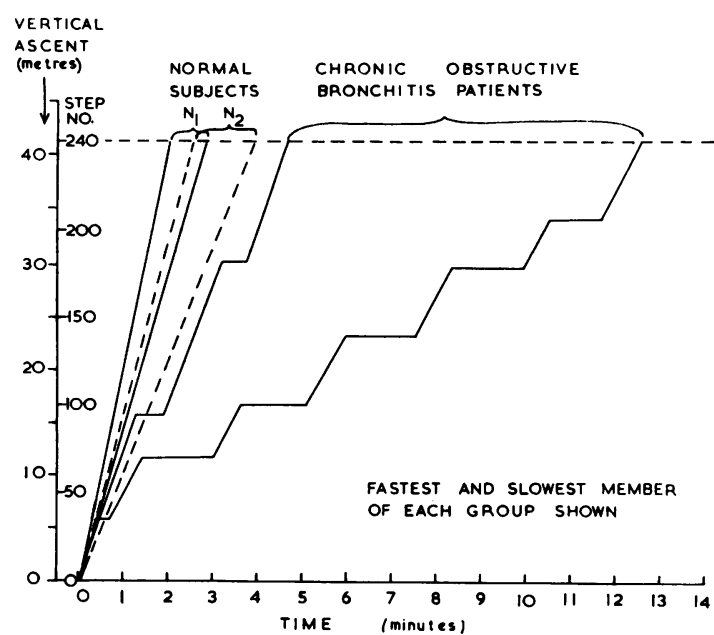

Fig. 2 Preferred ascent patterns.

in the first 30 seconds of climbing. There was a $4 \%$ reduction in stepping rate in the middle-aged normal group at the same stage, and no reduction at all in the healthy young group. Re-tests with two subjects showed a high degree of reproducibility in these results (Table 3).

\section{AVERAGE POWER OUTPUT}

When the average power outputs for spontaneous
Table 3 Reproducibility of spontaneous ascent patterns

\begin{tabular}{|c|c|c|c|c|}
\hline \multicolumn{4}{|l|}{ Individual ascent patterns } & $\begin{array}{l}\text { Total ascent } \\
\text { time(s) }\end{array}$ \\
\hline \multicolumn{4}{|c|}{$\begin{array}{l}\text { DB 1st trial W 36/R 37/W 37/R 59/W 66/R 75/W } 63 \\
\text { DB 2nd trial W 45/R 40/W 53/R 72/W 50/R 66/W 71 } \\
\text { AG 1st trial W 78/R 42/W 74/R 48/W 68 } \\
\text { AG 2nd trial W 82/R 36/W 68/R 56/W 58 }\end{array}$} & \\
\hline \multirow[b]{2}{*}{ Indices of exertion } & \multicolumn{2}{|c|}{ Subject $1(D B)$} & \multicolumn{2}{|c|}{ Subject $2(A G)$} \\
\hline & $\begin{array}{l}\text { First } \\
\text { trial }\end{array}$ & $\begin{array}{l}\text { Second } \\
\text { trial }\end{array}$ & $\begin{array}{l}\text { First } \\
\text { trial }\end{array}$ & $\begin{array}{l}\text { Second } \\
\text { trial }\end{array}$ \\
\hline $\begin{array}{l}\text { Exercise heart rate } \\
\text { (beats/min) } \\
\text { Increase in heart rate }\end{array}$ & 144 & 140 & 136 & 136 \\
\hline $\begin{array}{l}\text { (beats/min) } \\
\text { Increase in blood lactate }\end{array}$ & 68 & 64 & 52 & 56 \\
\hline Rating of perceived exertion & 13 & $13^{1 \cdot 42}$ & $1^{0.9}$ & $12^{1 \cdot 21}$ \\
\hline
\end{tabular}

$\mathbf{W}=$ working; $\mathbf{R}=$ resting.

ascent patterns were compared there was a significant difference between the groups, the middle-aged normal subjects and the patients attaining only $74.4 \%$ and $36.4 \%$ respectively of the values attained by the youngest group (Table 4).

MAXIMUM ANAEROBIC POWER

The maximum anaerobic power of young subjects was found to be significantly higher $(P<0.001)$ than that of the other two groups, between which there was no significant difference (Table 4). There was also a 
Table 4 Power output during preferred ascent patterns in relation to maximum anaerobic power (mean $\pm S E M$ )

\begin{tabular}{ccll}
\hline & $\begin{array}{l}\text { Group 1: } \\
\text { Young } \\
\text { normal subjects } \\
(n=10)\end{array}$ & $\begin{array}{l}\text { Group 2: } \\
\text { Middle-aged } \\
\text { normal subjects } \\
(n=10)\end{array}$ & $\begin{array}{l}\text { Group 3: } \\
\text { Middle-aged } \\
\text { patients } \\
(n=10)\end{array}$ \\
\hline $\begin{array}{c}\text { Max. anaerobic } \\
\text { power (watts) } \\
\begin{array}{c}\text { Average power } \\
\text { output (watts) }\end{array}\end{array}$ & $1047 \pm 84$ & $815 \pm 37$ & $657 \pm 49$ \\
\hline
\end{tabular}

significant relationship $(r=0.76)$ between the maximum anaerobic power and climbing power output of the young subjects and for all subjects considered together $(r=0.73)$. When the middle-aged normal subjects and patients were considered separately there was no significant relationship $(r=0.26$, $r=0 \cdot 21$ ).

\section{RATING OF PERCEIVED EXERTION}

Mean values obtained from the five indices of exertion associated with spontaneous ascent patterns revealed no significant difference between patients and their age-matched controls, nor between the middle-aged controls and the young group (Table 5). Rating of perceived exertion correlated with heart rate $(r=0.78)$. There was also a significant relationship $(r=0.78)$ between post-exercise blood lactate levels and rating of perceived exertion and between postexercise heart rate and blood lactate $(r=0.80)$. Peak expiratory flow rate was not changed; there was thus no evidence of exercise-induced bronchoconstriction in any group.

AVERAGE POWER OUTPUT ( $W_{a v}$ ) AND FEV Fi. $_{1.0}$

A significant relationship $(r=0.91)$ was found between average power output and $F E V_{1.0}$ for the total number of subjects considered together and in the patient group alone $(r=0.74)$, but there was no significant relationship within either normal group when separately treated (Fig. 3).

Table 5 Indices of exertion when subjects arrived at top of staircase after climbing at preferred rates

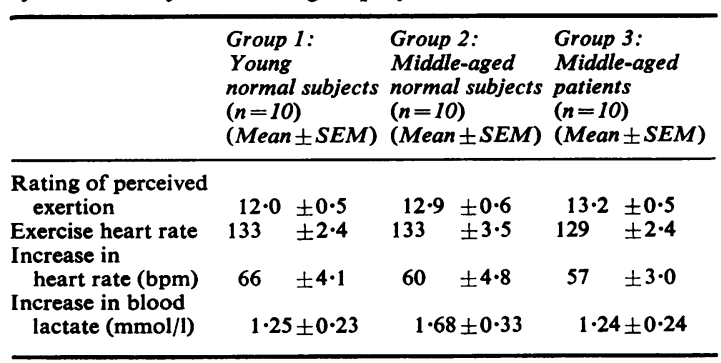

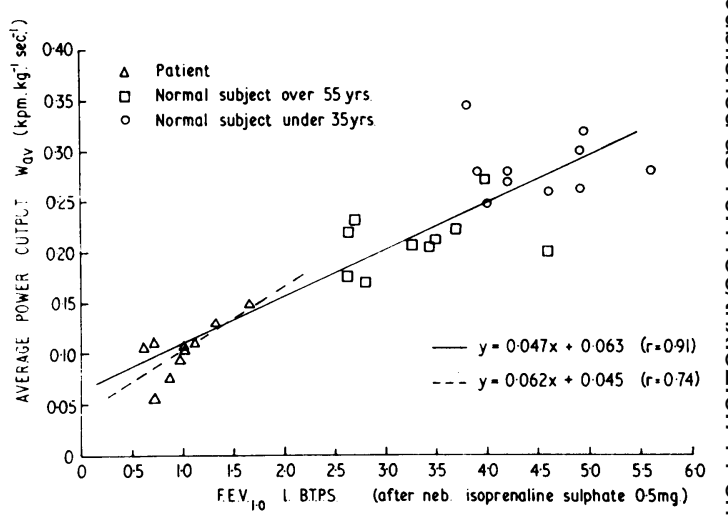

Fig. 3 Relationship between average power output and $F E V_{1.0}$. There is a significant correlation between $W_{a v}$ and $F E V_{1.0}$ in the total sample $(n=30 ; r=0.91$; $\mathrm{P}<0.001)$ and in the patient group alone $(n=10$; $r=0.74 ; \mathrm{P}<0.01)$, but no significant relationship within either normal subject group when treated separately.

\section{Discussion}

The strenuous nature of stairclimbing is well illustrated by this study. Normal young subjects are easily able to sustain a high power output. On shorter staircases they may even raise their power output very much higher by running though they may be breathless for a short time afterwards. Exercise at such a high level relies upon the capacity of the anaerobic mechanisms of the body, and it is the decline with age of anaerobic power (Margaria et al., 1966) and strength (Aastrand and Rodahl, 1970) which presumably explains why older people prefer to climb:stairs more slowly than the young, assuming that no 3 mechanical (joint) factors are involved.

The study has also indicated that individual subjects appear to have an intuitive feeling for what constitutes an appropriate stepping rate and, moreover, this differs significantly between the two age $\frac{}{0}$ groups. It is known that exercise at a given intensity is perceived to be heavier by older subjects than by $\mathcal{N}$ young ones (Borg and Linderholm, 1967), and that in N everyday activities people can readily modify the N exercise intensity as a result of their perception of $\omega$ exertion. It is probable, therefore, that the rate set for stairclimbing is the result of self-determined pacing, $\stackrel{\circ}{=}$

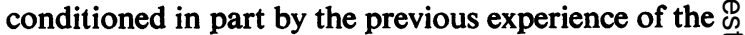
physical stress of stairclimbing. This hypothesis is further substantiated by the power output and $\frac{0}{\circ}$ perceived exertion data which show that while power $\stackrel{\mathbb{D}}{\mathbb{D}}$ output was significantly different between groups, the $\frac{?}{\mathbb{D}}$ stress experienced was identical, as indicated by the $\varrho$ physiological measurements.

From the above it may be assumed that subjects 
with chronic airways obstruction who are likely to experience respiratory stress in such a vigorous activity as stairclimbing would adopt patterns of ascent very much slower than those adopted by their healthy peers. In general, this was the case, but it was noted that patients appeared to make every effort to maintain as 'normal' a rate of climbing as their incapacity permitted, stopping for rests only when breathless. The problems of maintaining balance at very slow climbing rates and social acceptability seem to lead patients to prefer their spontaneous intermittent patterns to slower continuous rates. Thus, intuitively or otherwise, they are adopting patterns of exercise practised by mountaineers at altitude (Pugh, 1958) which extend their exercise tolerance beyond what would otherwise be allowed by their reduced aerobic capacity because they depend upon local muscle sources which may be little affected by airways obstruction (shown here by fairly normal anaerobic power values).

The absence of a significant relationship between average climbing power output and maximum anaerobic power for the middle-aged normal group is of some interest. The results seem to suggest that the group may underestimate their work capacity and are not prepared to stress themselves above a level which they perceive to be tolerable. By so doing, individuals may very well be contributing to a general decline in fitness and a lowering of work rate even in such habitual activities as walking and stairclimbing.

The low values for the post-exercise blood lactate concentrations are probably explained by the short duration of the work. Even when young fit subjects ran to the top of the staircase at high speed, the lactate level seldom exceeded $2 \mathrm{mmol} / \mathrm{l}$. Compared with other types of exercise of longer duration this is a low figure (Edwards et al., 1972), suggesting that lactate is not an important factor in the genesis of the perception of effort in stairclimbing.

The study illustrates how a subject's perception of effort may complement the physiological measures of working capacity. It may also be of aid to the clinician in deciding work rates in exercise tests. The need to study how people with disabilities adapt to their handicap in their normal environment is also highlighted. Recent work by Bassey et al. (1976) and McGavin et al. (1976) provides good examples of similar studies in patients of self-paced exercise performance.

We are grateful to Dr. N. B. Pride and the patients of the Bronchitis Clinic for their cooperation and to the Wellcome Trust for support.

\section{References}

Aastrand, P. O., and Rodahl, K. (1970). Textbook of Work Physiology, pp. 92-96. McGraw-Hill, New York.

Bassey, E. J., Fentem, P. H., MacDonald, I. C., and Scriven, P. M. (1976). The performance of elderly men using a self-paced walking test. Journal of Physiology, 256, 94P-95P.

Benedict, F. G., and Parmenter, H. S. (1928). The energy metabolism of women while ascending or descending stairs. American Journal of Physiology, 84, 675-698.

Borg, G. A. V. (1962). Physical Performance and Perceived Exertion. Lund, Gleerup.

Borg, G. A. V. (1970). Relative response and stimulus scales. Reports of the Institute of Applied Psychology, University of Stockholm, No. 1.

Borg, G. A. V. (1971). Psychological and physiological studies of physical work. In Measurement of Man at Work, edited by W. T. Singleton, J. G. Fox, and D. Whitfield, pp. 121-128. Taylor and Francis, London.

Borg, G. A. V., and Linderholm, H. (1967). Perceived exertion and pulse rate during graded exercise in various age groups. Acta Medica Scandinavica, Supplement, 472, 194-206.

Borg, G. A. V., Noble, B. J., and Sherman, M. A. (1968). A perceptual indicator of physical stress. Paper presented at Annual Convention of the American College of Sports Medicine, Pennsylvania State University, 2 May, 1968.

Campbell, E. J. M., and Howell, J. B. L. (1962). Rebreathing method of measurement of mixed venous PCO2. British Medical Journal, 2, 630-633.

Davies, C. T. M. (1971). Human power output in exercise of short duration in relation to body size and composition. Ergonomics, 2, 245-256.

Edwards, R. H. T. (1971). Peripheral factors influencing effort tolerance in chronic obstructive bronchitis. Scandinavian Journal of Respiratory Diseases, Supplement, 77, 107-111.

Edwards, R. H. T., Melcher, A., Hesser, C. M., Wigertz, O., and Ekelund, L. G. (1972). Physiological correlates of perceived exertion in continuous and intermittent exercise with the same average power output. European Journal of Clinical Investigations, 2, 108-114.

Hill, A. V., and Lupton, H. (1923). Muscular exercise, lactic acid, and the supply and utilisation of oxygen. Quarterly Journal of Medicine, 16, 135-171.

Hohorst, H. J. (1962). L (+)-Laktat Bestimmung mit Laktat Dehydrogenase und DPN. In Methoden der enzymatischen Analyse, edited by H. U. Bergmeyer, pp. 266-270. Verlag Chemie, Weinheim.

McGavin, C. R., Gupta, S. P., and McHardy, G. J. R. (1976). Twelve-minute walking test for assessing disability in chronic bronchitis. British Medical Journal, 1, 822-823.

Margaria, R., Aghemo, P., and Rovelli, E. (1966). Measurement of muscular power (anaerobic) in man. Journal of Applied Physiology, 21, 1662-1664.

Medical Research Council (1965). Definition and classification of chronic bronchitis for clinical and epidemiological purposes. A report to the Medical Research 
Council by their Committee on the Aetiology of Chronic Bronchitis, Lancet, 1, 775-779.

Pugh, L. G. C. E. (1958). Muscular exercise on Mount Everest. Journal of Physiology, 141, 233-261.

Skinner, J. D., Borg, G. A. V., and Buskirk, E. R. (1969). Physiological and perceptual characteristics of young men differing in activity and body composition. In Exercise and Fitness, edited by B. Don Franke, Proceedings of a Symposium presented in Champaign-
Urbana Campus, 25-26 April, 1969.

Waller, A. D., and de Decker, G. (1919). Bicycle compared with staircase ergometry. Journal of Physiology, 53, xliv-xlvi.

Requests for reprints to: Professor R. H. T. Edwards, क Department of Human Metabolism, University College Hospital Medical School, University Street, London, WC1E 6JJ, UK
ㅇ 